\title{
Design Thinking Approach for the Development of Theme Park Application
}

\author{
Tinnaporn Srisombut ${ }^{1} \cdot$ Supamas Thamlersak ${ }^{1} \cdot$ Phattharaporn Chaitantipong $^{1} \cdot$ Thitirat Siriborvornratanakul $^{1}$
}

Received: 25 August 2021 / Revised: 15 October 2021 / Accepted: 18 October 2021 / Published online: 13 November 2021

(C) The Author(s), under exclusive licence to Springer Nature Singapore Pte Ltd. 2021

\begin{abstract}
Theme entertainment businesses rely very much on providing their visitors with the most memorable experiences. To do so, top operators have put a considerable amount of effort and investment in their facilities and activities in their parks. However, after a customer interview, several pain points are still found such as long toilet queues, finding available parking lots, being unable to find the parked car, and no real-time thrill ride information/status. Similar with other domains in the tourism market, most of these problems are easy to solve with the help of having a smartphone application that delivers such information right to the customer's hands. This study outlines the development process of a theme park application based on a design thinking approach. Our MVP prototypes have obtained good feedback from potential users in both qualitative and quantitative usability tests.
\end{abstract}

Keywords Theme park application · Design thinking $\cdot$ Lean development $\cdot$ Usability testing $\cdot$ MVP prototype

\section{Introduction}

Theme parks are leisure attractions that offer their customers a mixture of excitement feeling and fantasy atmosphere. Theme entertainment industry is also a rising star in marketing and economy aspects [1]. In 2018, the industry has reached a new milestone where the attendance number at the top-ten theme park operators has exceed half a billion visits [2]. In 2019, the industry has continued to grow at the annual rate of four percent [3].

Several studies have mentioned the connection between memorable experiences and revisit intention [1]. Zambetta et al. [4] states that the memory of an event is even more

Thitirat Siriborvornratanakul

thitirat@as.nida.ac.th

Tinnaporn Srisombut

tinnaporn.sri@stu.nida.ac.th

Supamas Thamlersak

supamas.tha@stu.nida.ac.th

Phattharaporn Chaitantipong

phattharapo.cha@stu.nida.ac.th

1 Graduate School of Applied Statistics, National Institute of Development Administration, 148 Serithai Road, KlongChan, Bangkapi, Bangkok 10240, Thailand important than the event itself. The study further argues that past experiences of individuals were recalled only by a few important events. Another study also concludes that long-term memorable experiences have a significant impact on revisit intention [5]. Therefore, providing positive memories to customers is essential in this competitive market.

Unlike other domains of the tourism industry, the use of smartphone-based applications for on-site touristic experience in theme park attractions is relatively limited. Only, a few studies emphasize the user's perception of attraction related apps [6]. Moreover, despite of the fact that most of the global top theme park operator already have launched their own mobile applications available for the local theme park in Thailand. Although the decision to develop prototypes of theme park applications in this study was obtained from extracting users' needs, it is a good opportunity to fill in the missing gap. 


\section{Literature Review}

\section{Lean Product Development and Minimum Viable Product}

Lean product development is an approach for creating new products in situations where there are various uncertainties while resources and finance are limited. To avoid developing a product that is failed, developers need to 'get out of the building' to meet their potential customers and learn what the customers' needs really are. This approach proved to be time and cost effective since developers can foresee their possible mistakes at the early stage of development.

Minimum Viable Product (MVP) is the smallest set of features that represents the proposed product uses for validating the product's concepts. MVP which was received negative feedback may need a revision. The situation where developers need to change the product concepts is known as 'Pivoting' which is an essential characteristic of lean product development [7].

\section{User-Centered Design and Usability Testing}

User-centered design (UCD) is an approach to create a product that satisfies user requirements. As its name suggested, UCD places the targeted users at the center and require their involvement in every design stage. The main characteristic of this approach is the process of analysis and extracting the users' needs through various interactive designs, a process of creating an interactive product that not only focus on the functionality and appearance but also how users interact with it [8], then translates the needs into product's functionalities and designs [9].

Usability is a property for measuring how well targeted users interact with a prototype. Usability is one of the key components for user experience design, second only to product utility. To ensure that the proposed product will be able to serve the users' needs, usability testing must be conducted in every prototype to identify the following five elements, effectiveness, efficiency, engagement, error tolerance, and ease of learning [10].

\section{Design Thinking Process}

[11] Design thinking (DT) is a cyclical process useful for handling complexities in creating innovations. The fundamental of this methodology is based on collaborating with others to gain an understanding of the human's needs through real-world information (Fig. 1). DT consists of five stages, which are.
1. Empathize: establishes an emphatic understanding of the problem by consulting experts or communicating with the customers themselves.

2. Define: analyses information obtained from the previous stage to define the core pain-points.

3. Ideate: generates ideas to solve the defined problems.

4. Prototype: create the MVP prototypes to test the idea.

5. Test: test the prototype to gather more ideas.

The philosophy of design thinking helped boosting creativity and innovativeness in various fields. A recent study [12] has emphasized the advantages of applying DT in tourism educations where DT was used as a teaching/ learning tool in 3 different courses in both BA and MA in Constantine the Philosopher University, Nitra, Slovakia. At the end of the experiment, both students and teachers gave positive opinions on DT, including enhancing students' communication and teamwork, which resulted in boosting creativity. Moreover, students were able to bring concrete problem-solving ideas in the tourism business, one of which is a prototype of a mobile application which provided a complete information of all archaeological sites around the city.

\section{Prototype}

[13] The prototype is an experimental model of a product created for communication with the targeted users. The benefits of using a prototype in the design process are (1) idea generation, (2) adjustability and (3) cost and time efficiency. Prototype fidelity is the level of presentation and functionality of the model, compares to the proposed product.

\section{Low Fidelity Prototype}

Low fidelity prototype is a low-detail, incomplete representation with limit functions, usually used in the early stage of the design process for product introduction and gathering user responses.

\section{High Fidelity Prototype}

High fidelity prototype is a high-detail representation with a higher degree of functionalities. Due to its complexity, this type of prototype is usually applied at the later stage where more specific user feedbacks are needed.

\section{Mobile Application Development}

The success of a mobile application highly depends not only on its functionalities but also on the overall user experience; therefore, the user-center design and usability 
Fig. 1 Design Thinking Process (Adapt from Siang, and the International Design Foundation [10])

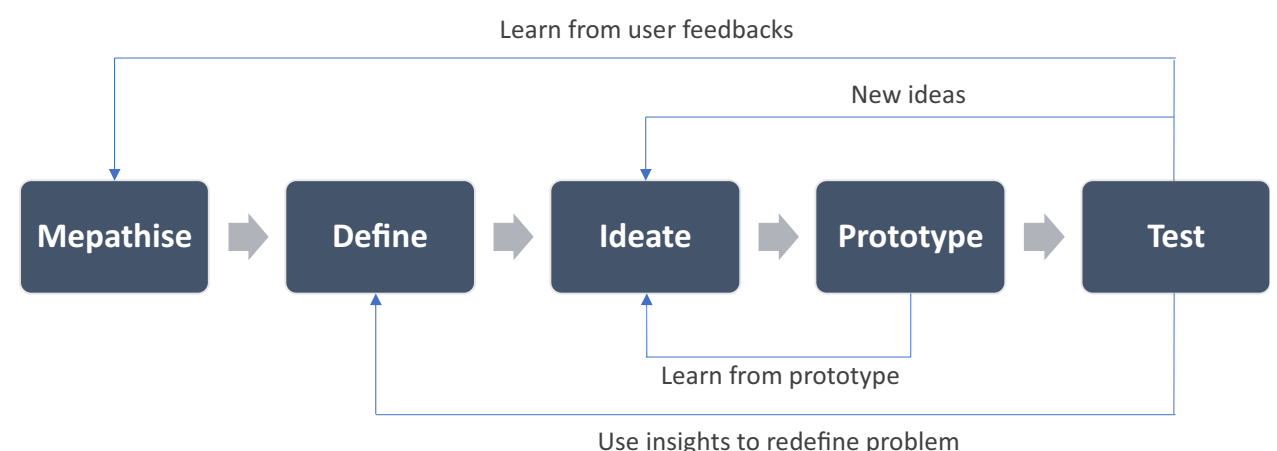

testing play an important role during the development. A study [14] has demonstrated how user-center design and usability testing are involved in the development of a mobile application for contemporary architecture tourism in Portugal. The process involved creating a benchmark from already existed apps related to the contemporary architecture tourism as well as conducting an interview with architects to gain information and defines problems. A prototype was built according to the insight obtained from the previous stage. The final stage was conducting on usability testing using a qualitative analysis with pre-defined questions. The application prototype obtained from this study received a positive impact from its targeted users.

\section{Methodology}

\section{Empathize}

To define the demographics of the potentially targeted users, we had a short interview with an administrator of a Facebook page named "Suansanook Thai: Thailand Amusement Enthusiast Community". We were informed that the largest and most active users of the page are age between 25 and 35 years old. Moreover, most of these users had experiences visiting theme parks in other countries; hence, we implied that the financial status of these users is at least above average. Although this research aims to create a sample application for theme parks in Thailand, the fact that most of the potentially targeted users have experiences visiting theme parks abroad has helped us analyze competitors and define a concrete idea which functions must be included in our app.

We then conducted a qualitative analysis by interviewing 6 research samples which consist of 3 males and 3 females age between 25 and 35 years old who had been to at least one theme park overseas. Personas were created based on the obtained information, as shown in Fig. 2.

A comparative analysis of both direct and indirect competitors was conducted to find out the currently common "pain points" shared among them. The analysis summary was shown in Fig. 3; however, the details of the analysis will be elaborated in the next section.

At the end of this stage, we understood the needs and pain points of the targeted users as well as a general idea of our competitors, as shown in Fig. 4.

\section{Define}

The user needs and pain points were grouped into 6 categories, which are missing features, missing information, dissatisfying experience, map \& location awareness, UX/ UI friendliness, and Personal Features. After brainstorming and careful discussions based on the importance of user need and user satisfaction matrix, we categorized the user needs into three categories, which are opportunity, competitive market, and not worth going after (in this study), as shown in Fig. 5. The obtained final results were 4 competitive, 6 opportunities, and 3 not worth going, as shown in Fig. 6.

\section{Ideate}

User needs and pain points which were defined in the previous stage were transformed into features. Using the user need and satisfaction matrix, these features then were categorized into three categories, which are must-have features, performance features, and delighter features. Must-have features are common features that are available in most of the existing competitors. Performance features are needed features but are lacking in most apps. Delighter features are features that user may not yet look for, but have potential benefits or may be able to alleviate some pain points, as shown in Fig. 7.

Finally, we obtained 4 must-have features, 3 performance features, and 3 delighter features. Our MVP consisted of all must-have features. However, due to the short timeline and limit resources, the performance feature's queue reservation and all delighter features will not be included in this study. 


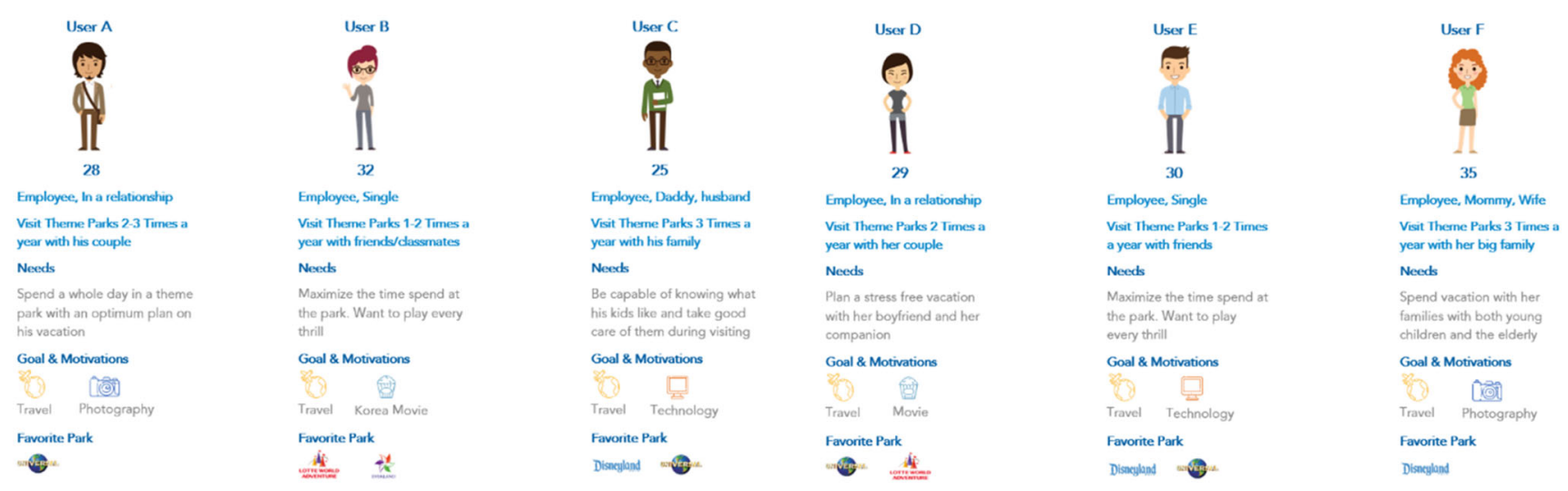

Fig. 2 User Personas Cartoon group of people. Photograph by Kamason, via cleanpng.com (https://www.cleanpng.com/png-cartoon-animatedcartoon-people-human-animation-7385556/)

Fig. 3 Summary of competitors analysis

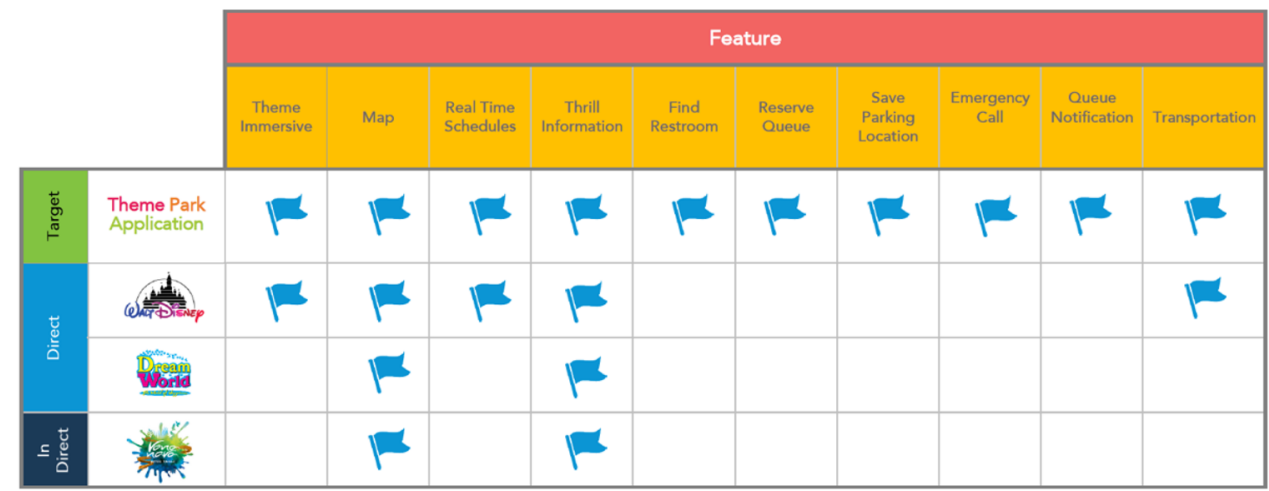

Fig. 4 User needs and painpoints
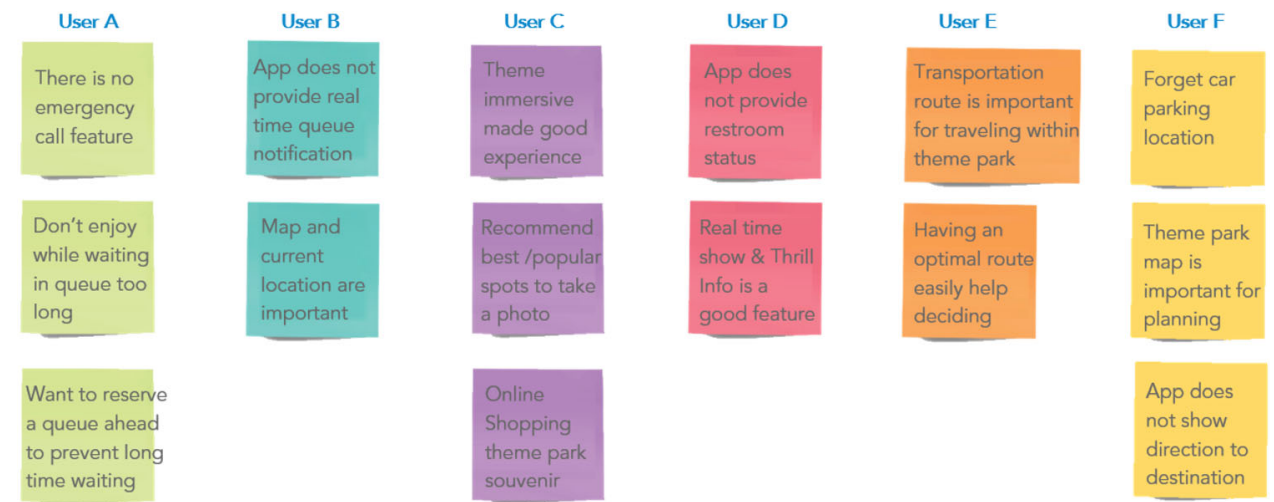

\section{Prototype}

purposes of this simulation are to demonstrate our MVP features and gather feedback from potential users (Fig. 8).

\section{Home Page}

The prototype starts with a home page displaying the overall theme park area and the current location of the user is also displayed on the map as an object as shown in Fig. 9. Users are able to select specific features to be displayed as another layer on the map by tapping the dropdown icon at the top of the page as shown in Fig. 10. 
Fig. 5 Categorized user needs and pain-points
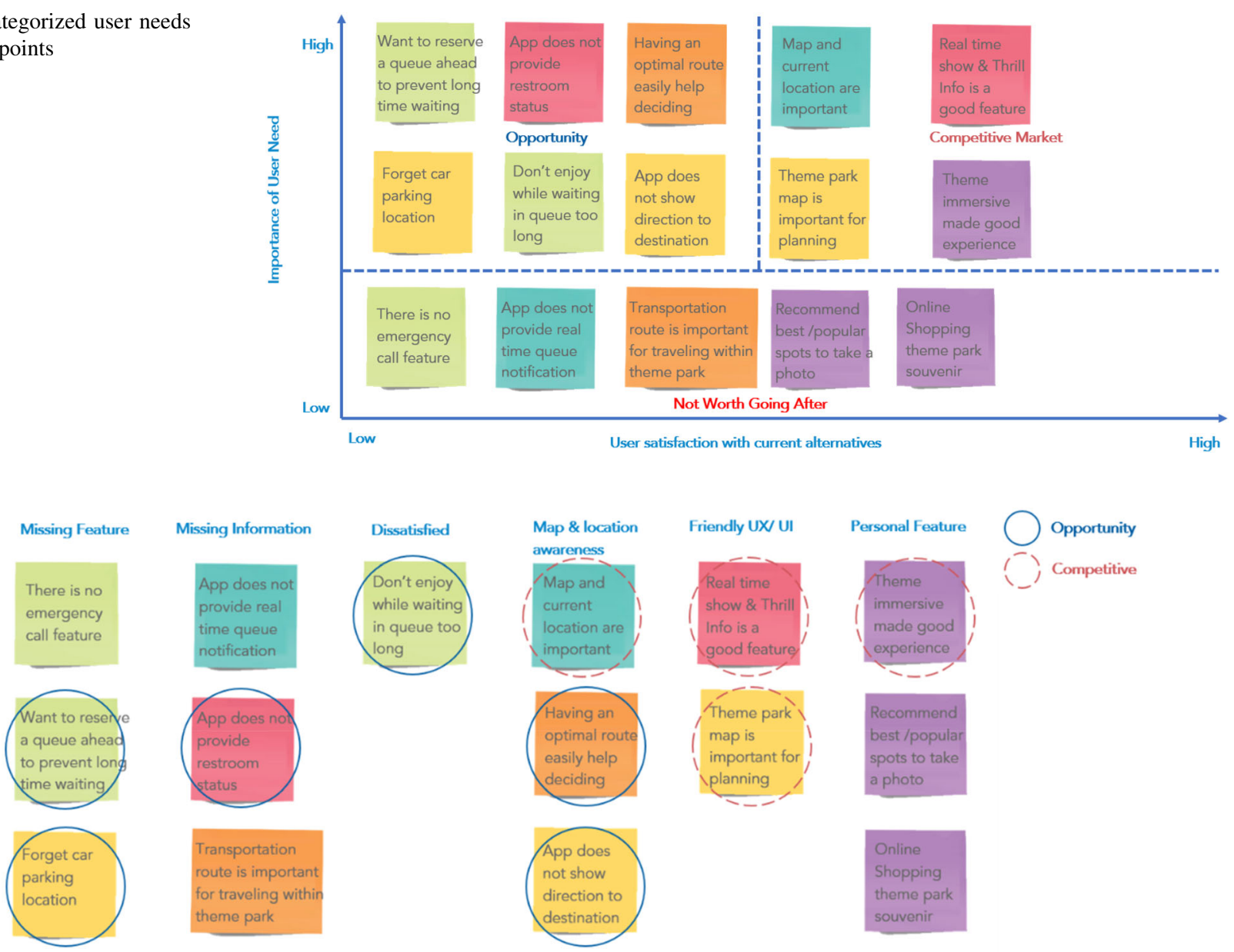

$\bigcirc$ Opportunity

(1) Competitive

Fig. 6 Affinity diagram

\section{Benefit}
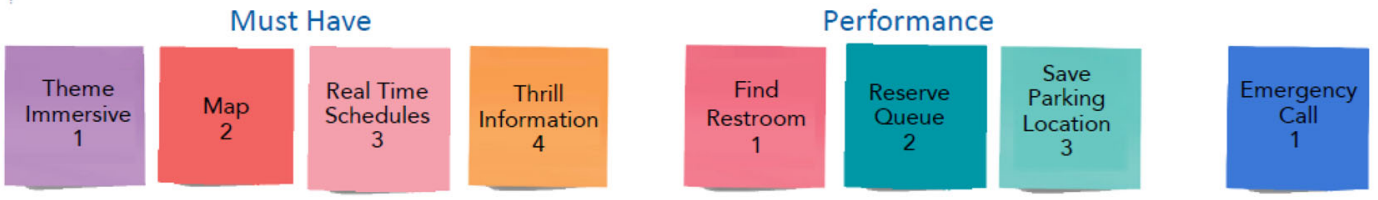

Delighter

\section{Features}
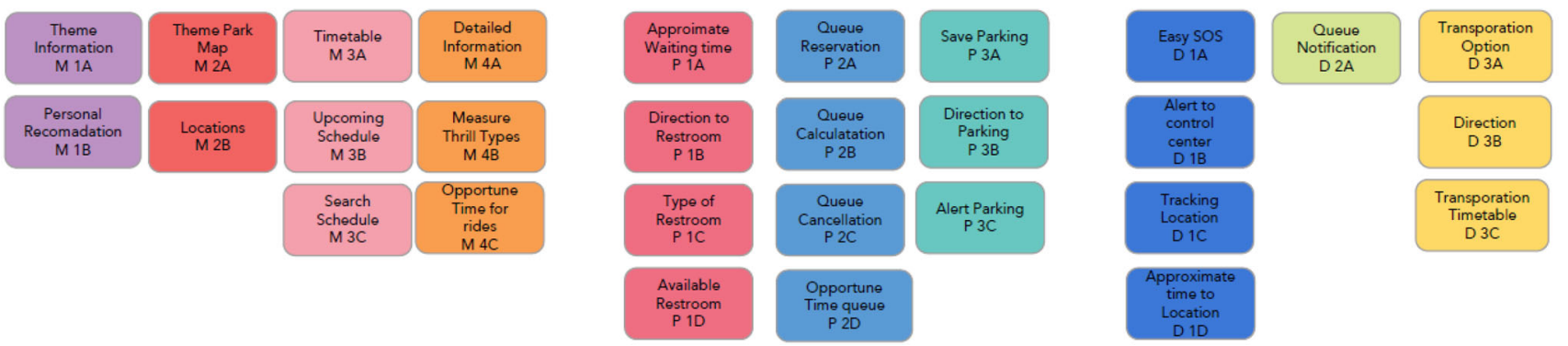

Fig. 7 Categorized features 


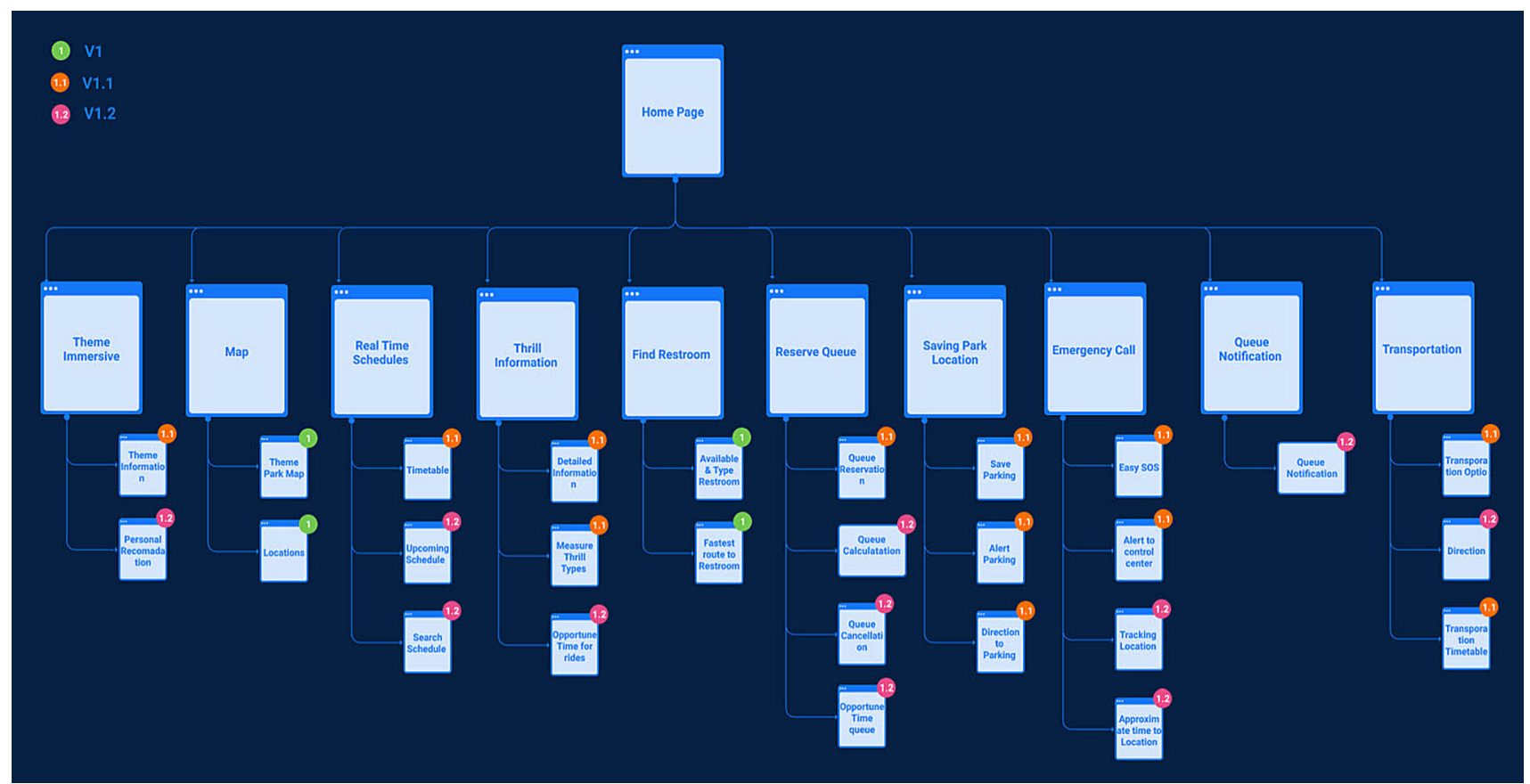

Fig. 8 Application Flow

Fig. 92008 Hong Kong Disneyland Map. Photograph by Jacky Chiang, via Pinterest (https://www. themeparkbrochures.net/maps/ hong-kong-disneyland/) Menu Icons, Photograph by Anonymous, via pinclipart.com (https://www.pinclipart.com)

Fig. 10 Category items to show theme park landmarks Theme Park Icons. Photograph by Smashingstocks, via flaticon.com (https://www. flaticon.com/authors/ smashingstocks)
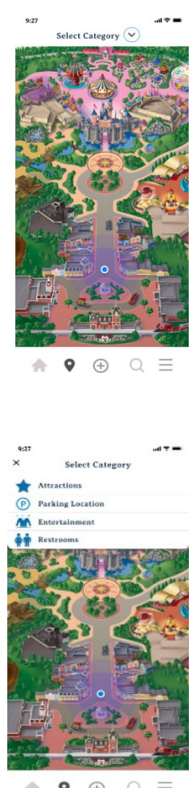

\section{Dropdown Menu}

By selecting each category in the dropdown menu, the selected component will be displayed as pop-up pins at the various place across the map.

- Attraction menu: because attractions (or thrill rides) are the highlight and the main purpose of a theme park, there usually have a long queue waiting for the rides. This situation is one of the dissatisfied experiences mentioned in our users' interviews. Therefore, to help visitors better grasp the current queue status ahead of their arrival, our prototype simulated an estimated queuing time and walking time from the current user location to each ride. By tapping the 'Get detail' button, useful information of the select ride, such as age limitation, open hour as well as a detailed navigation route, will be displayed, as shown in Fig. 11.

- Parking location menu: a set of features that helps visitors efficiently find available parking spaces and save the location of the parked car. These features included real-time parking lot availability information as well as navigation routes from anywhere within the theme park to the parked car, as shown in Fig. 12.

- Entertainment menu: there are a large variety of show and entertainment events across a theme park. To help visitors not missing their favorites shows, this feature provides information such as the show's schedule, show duration, recommended age, and duration \& navigation to the event, as shown in Fig. 13.

- Restroom menu: restroom's long waiting queue is of the most mentioned problems during our user research. This feature allows users to check for the closest available restroom from their current location. It also provides useful information such as estimated queuing status, restroom's capacity \& lavatories as well as navigation route, as shown in Fig. 14 
Fig. 11 High-Fidelity Design of Attraction Feature Fantasy Castle Photograph by

Anonymous, via

wallpaperaccess.com (https:// wallpaperaccess.com/cartooncastle)

Fig. 12 High-Fidelity Design of Save Parking Feature Parking Background Photograph by Vikki Turner, via themouseforless.com (https:// www.themouseforless.com/ blog_world/where-to-park-atdisneyland/)

Fig. 13 High-Fidelity Design of Entertainment Feature Marching Band Photograph by noodledoodle, via vecteezy.com (https://www.vecteezy.com/ vector-art/154970-animalmarching-band-charactervectors)

Fig. 14 High-Fidelity Design of Restroom Feature People Pack, Photograph by Awesome People, via assistivecards.com (https://assistivecards.com/en/ pack/people) Restroom Icons, Photograph by Freepik, via flaticon.com https://www.flati con.com/search/2? word=restroo $\mathrm{m} \&$ order_by $=4 \&$ type $=$ icon)
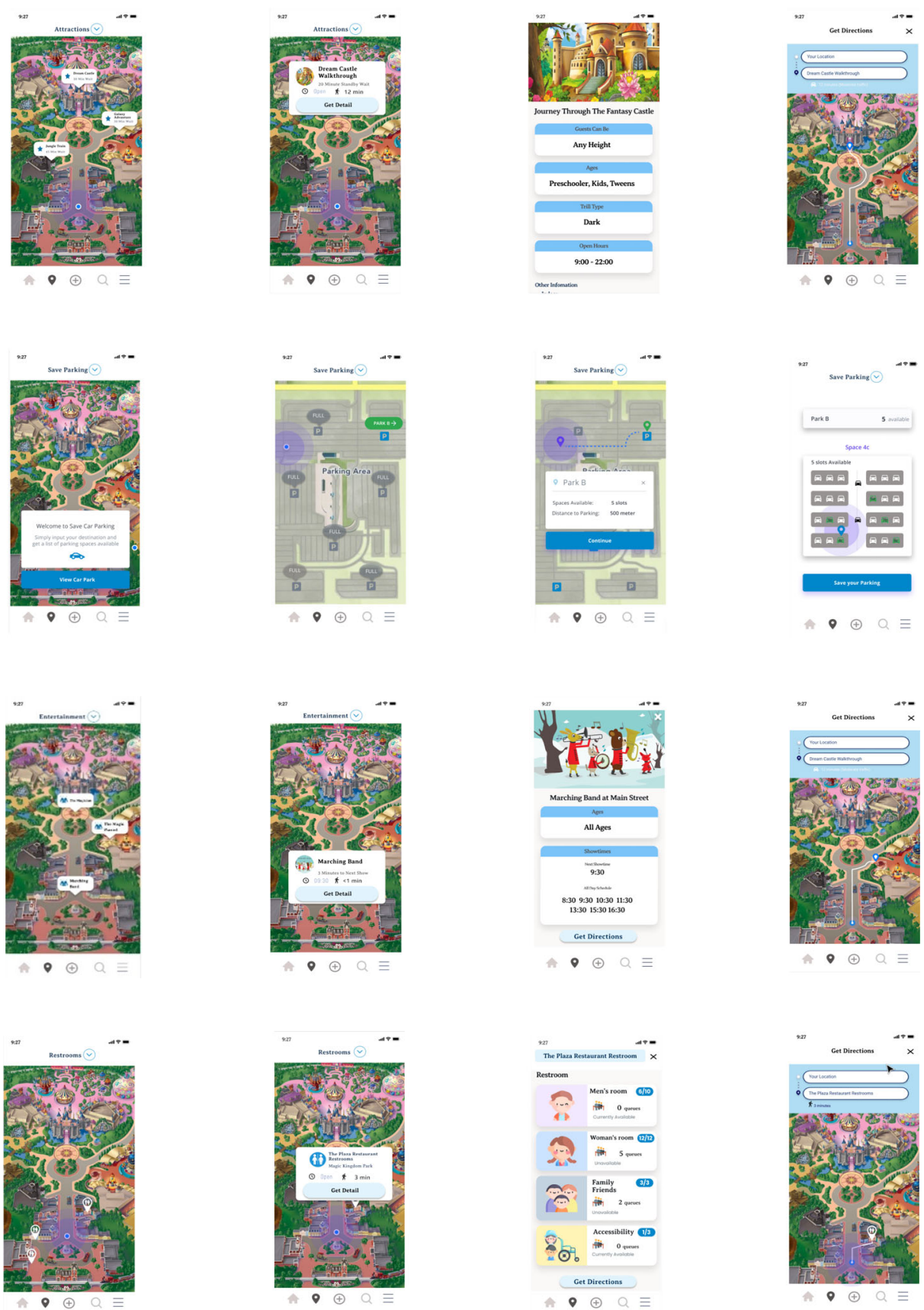

Links access to the prototypes were sent to approximately 25 users via an instant messaging platform. Users were asked to answer an $\mathrm{A} / \mathrm{B}$ testing questionnaire on Google Form. The selected users were age between 23 and 35 years old who have been to theme parks domestically and/or internationally. There are 19 participants who gave us feedback. 


\section{Second Usability Testing: MVP Prototype Version 1.0}

MVP Prototype Version 1.0 consists of all must-have features plus the winner from the first test. Participants are the same 19 people from the first test. Instead of using Google Form, we switched to Maze, a prototype testing tool on Figma, which is more dynamic and allows us to create missions for participants to follow. Maze also allows us to gather deeper information.

\section{Third Usability Testing: Performance Feature 2 (Parking Location)}

Two versions of parking location features were created. The same 19 people plus another 11 new users have participated in this test. The A/B testing was conducted with Maze.

\section{Fourth Usability Testing: MVP Prototype Version 1.1}

MVP prototype version 1.0 consists of the improved version of MVP prototype version 1.0 plus the winner from the third test. Six new participants were chosen with the same selecting criteria. We performed a deep interview for each participant after they finish the missions we created on the Maze. The detail and result of each test will be discussed in the next section (Fig. 15).

\section{Result and Analyze}

\section{Comparative Analysis of Competitors}

\section{Disneyland}

Each Disneyland around the world has its own application. Every application has similar features with a slightly different UI. Disneyland application provides a map of the whole theme park area and the location of every facility within. The app also provides information and schedule of thrill rides and shows. Online souvenir shopping and many others feature are also available. However, features such as real-time restroom status, parking location, queue reservation and notification, and emergency calls are not available in the app.

\section{Dreamworld}

Dream World is a theme park located in Pathum Thani, Thailand. Currently, the park does not provide any mobile applications. Information is available on its website; otherwise, on paper brochures that are provided at the entrance. Moreover, the website provides limit information including open and close time, thrill information and schedule, and static maps.

\section{Vana Nava}

Vana Nava is a water park located in Hua-Hin, Thailand. Apart from water activity, Vana Nava also consists of rides and attractions. Same as Dreamworld, currently Vana Nava

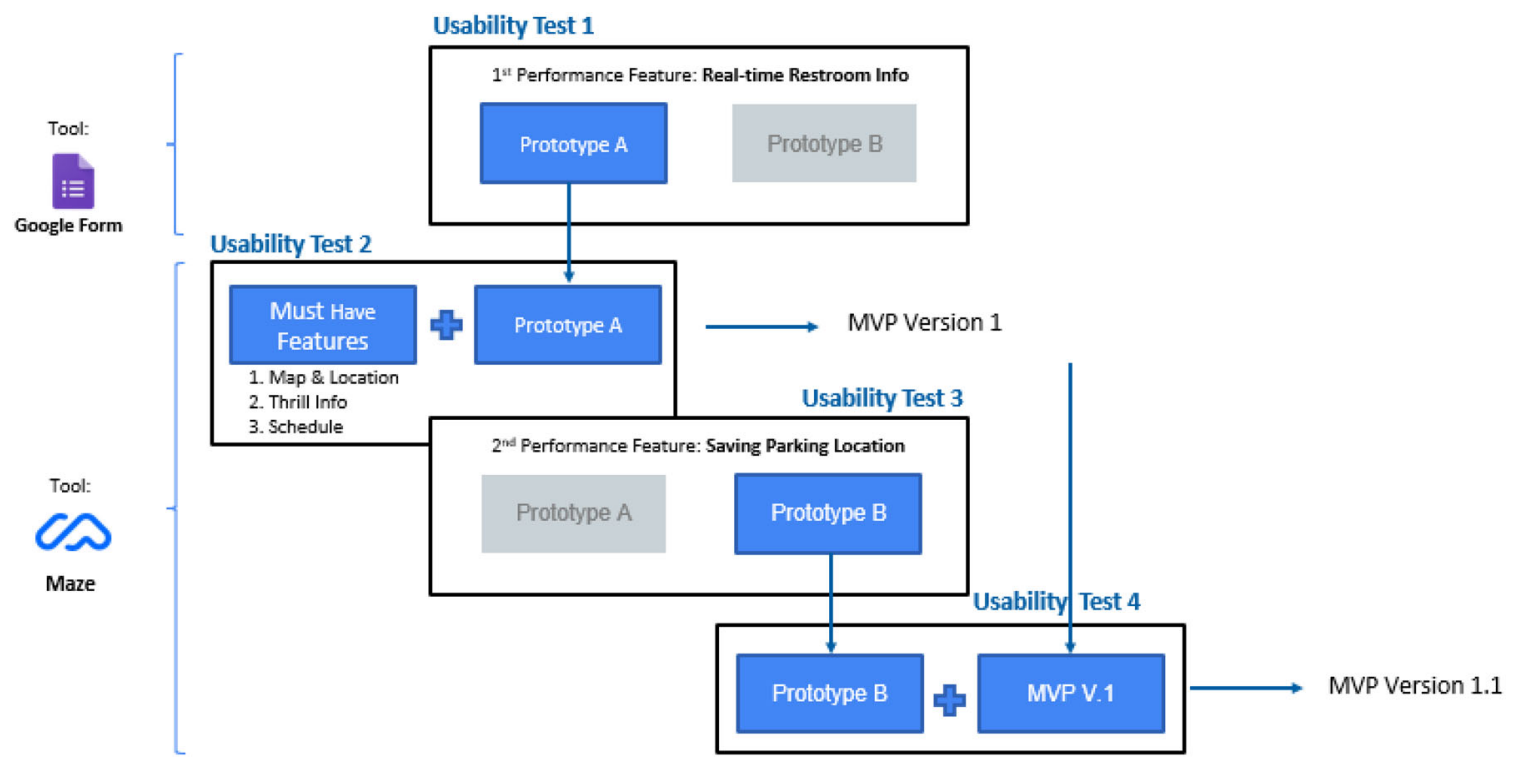

Fig. 15 UX Validation via MVP prototype 
does not provide any mobile application. Information is available on its website or paper brochures. Its website, however, provides slightly more information compared to Dreamworld's.

From the comparison, it is clearly seen that thematic park mobile application is a blue ocean market in Thailand. Furthermore, even the application from the top theme park operator is still lack in some features which, according to our finding from user interview, is needed.

\section{Usability Testing Result}

\section{First Usability Testing: Performance Feature 1 (Real-time Restroom Info)}

We developed 2 versions of our first performance feature, which is the real-time restroom information, then conducted an A/B testing using a questionnaire on the Google Form. The total participated users in this test were 19 persons $(n=19)$.

Prototypes Both Prototype A and Prototype B consist of comparable functions but different user interface.

Mission Scope We asked users to thoroughly test both prototypes then rate each prototype in three aspects (scale 0-5), as shown in Table 1.

The average score of Prototype A is $4.3(\bar{x}=4.3)$ and Prototype B is $3.5(\bar{x}=3.5)$. Prototype A also got a higher score in every aspect. The result indicates that, from users' perception, Prototype A is more usable than Prototype B. Therefore, we decided to proceed to the next version with prototype A.

\section{Second Usability Testing: MVP Prototype Version 1.0}

We combined the real-time restroom feature (prototype A version) with every must-have features to create the MVP prototype version 1.0 then conduct a usability testing using Maze, Maze provides quantitative data likes success rate, misclick rate, heatmap and duration users spend on each screen. Participants in this test were also 19 persons ( $\mathrm{n}=19)$.
Prototype The MVP prototype version 1.0 consists of all must-have features at the backend. The selectable menus, as the frontend, are attraction info, entertainment info, and restroom info (prototype A version from the previous step).

Mission Scope We created three missions for each selectable menu in Maze, then asked the participants to accomplish each mission. Participants are also able to give up if they find the tasks too hard. We also asked participants to rate the prototype and give us feedback. Everything users done was recorded and reported to researchers.

- Mission 1: From home page, access the Attractions menu and choose the attractions with the shortest waiting time and find the direction to the selected attraction.

- Mission 2: Go to the home page, access the Entertainment menu and find information about the showtimes of 'The Magic Piano Player' and find the direction to the event.

- Mission 3: Find the nearest restroom and check the availability of men's restrooms and navigate to the restroom.

The overall result of the usability testing is 4.5 , which indicates that the prototype is usable and satisfiable. After prioritizing user feedback, we also got an idea of what to be improved in the next version (Tables 2, 3, 4). (the correct signs in the approve column).

\section{Third Usability Testing: Performance Feature 2 (Parking Location)}

Again, we develop 2 versions of another performance Feature which is saving parking location. The two versions then were conducted another A/B testing using a questionnaire on Maze. Participants in this test were 30 people $(n=30)$. The score from the A/B Testing was measured and calculated using the System Usability Scale (SUS).

Prototype Prototype A and Prototype B contain identical features but with different user interface.
Table 1 Average score of each real-time restroom info prototype

\begin{tabular}{lll}
\hline Assessment topic & Prototype A & Prototype B \\
\hline 1. Difficult-easy to use & 4.0 & 3.0 \\
2. The information is complete and useful to you & 4.5 & 4.0 \\
3. The length of time that you take to access the information & 4.5 & 3.5 \\
$\bar{x}$ & 4.3 & 3.5 \\
\hline
\end{tabular}


Table 2 Average scores of the overall MVP prototype version 1.0

\begin{tabular}{ll}
\hline Assessment Topic & Score \\
\hline 1. Difficult-easy to use & 4.5 \\
2. The information is complete and useful to you & 4.6 \\
3. The length of time that you take to access the information & 4.9 \\
$\overline{\boldsymbol{x}}$ & 4.5 \\
\hline
\end{tabular}

Mission Scope Participants were asked to access to the 'Parking Location' menu and look for an available parking space then save the location and find the direction back to the parked car. Users also gave feedbacks at the end of the test.

The results of the A/B Testing analysis in the System Usability Score were calculated from the score of questions. The final score is between the range of 0-100. If the score is less than 50 , it is not acceptable. It is marginal

Table 3 Users' feedback on attractions and entertainment Menu

\begin{tabular}{|c|c|c|c|}
\hline Comment & No. of comment & $\%$ & Approve \\
\hline Pop-up is too big/it should be able to click on any empty space to make the box disappear & 6 & 32.0 & $\boldsymbol{\nu}$ \\
\hline Showing the entertainment name on the map & 5 & 26.0 & $\boldsymbol{V}$ \\
\hline I can't return to the map page from the info page & 2 & 11.0 & $\boldsymbol{V}$ \\
\hline Need User manual & 4 & 21.0 & $\times$ \\
\hline Showing waiting times on the map page & 1 & 5.0 & $\times$ \\
\hline The Font size of Dropdown menu is too big & 1 & 5.0 & $\times$ \\
\hline
\end{tabular}

Table 4 Users' feedback on restroom menu

\begin{tabular}{|c|c|c|c|}
\hline Comment & No. of comment & $\%$ & Approve \\
\hline 1. Adjust the Format of the Feature Menu and increase the size of the Font to make it clear & 7 & 36.84 & $\boldsymbol{\sim}$ \\
\hline 2. Showing the location to be clear by adding a symbol & 6 & 31.58 & $\checkmark$ \\
\hline 3. Adjust the Map to show it to be clear and understandable & 4 & 21.05 & $\boldsymbol{\sim}$ \\
\hline 4. Edit the restroom location to be clearer & 4 & 21.05 & $\checkmark$ \\
\hline 5. Add more detail about the function of the bathroom status & 2 & 10.53 & $\times$ \\
\hline
\end{tabular}

Fig. 16 System usability scale of both Saving Parking Location prototype (Adapt from Andrew Smyk [15])

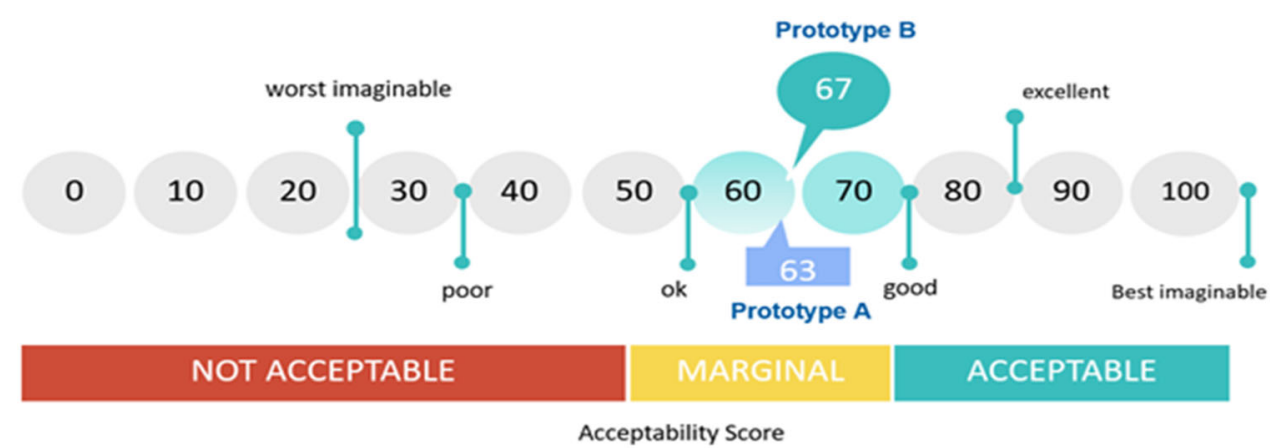


Table 5 Users' feedback on Saving Parking Location menu

\begin{tabular}{|c|c|c|c|}
\hline Comment & No. of comment & $\%$ & Approve \\
\hline 1. No need to manually select a parking space, but automatically the detect location from Map & 13 & 43.33 & $\checkmark$ \\
\hline 2. Minimize the screen size when you need press due to driving. You don't want to press too much & 10 & 33.33 & $\checkmark$ \\
\hline 3. The current location route to the parking spot is unclear & 9 & 30.00 & $\checkmark$ \\
\hline 4. Change the color of the full parking area & 4 & 13.33 & $\checkmark$ \\
\hline 5. Showing the distance from the driver to the parking space & 2 & 6.67 & $\boldsymbol{\sim}$ \\
\hline
\end{tabular}

between 60 and 80. If a score is 80 and above, it is acceptable. Both prototypes were marginal as they got the score of 63 and 67 consequently, as shown in Fig. 16. Although only a small margin, prototype B was selected for the next development (Table 5).

After analyzing user feedbacks, we decided to take every comment for improvement in our next MVP.

\section{Forth Usability Testing: MVP Prototype Version 1.1}

We combined the winner of the saving parking location with the improved MVP prototype version 1.0, obtaining the MVP prototype version 1.1 as a result. This time around, we performed a fully qualitative usability testing by interviewing 4 participants while they were doing the mission we created in Maze.

Prototype MVP prototype version 1.1 consists of all improved version of features from the MVP prototype version 1.0 combined with the improved versions of the winner of saving parking feature from the previous stage (prototype B).

Mission Scope We created missions in Maze and asked users to finish the missions one by one. We interviewed the user after they had finished each mission. Users were also asked for overall opinions about the app as well as rate the usefulness and ease of use of the app.

- Mission 1: From the home page, access the Attractions menu and choose the attractions with the shortest wait times and find directions to the attraction place.

- Mission 2: From the home page, access the Entertainment menu and choose the Entertainment data to find showtimes of The Magic Piano Player and find directions to The Magic Piano Player place.

- Mission 3: Find the nearest restroom and check that men's restrooms are available and show directions map to the restroom

- Mission 4: From the home page, access the feature Parking Location choose a parking space to park the car

Table 6 Usability Testing Summary

\begin{tabular}{|c|c|c|c|}
\hline Assessment/ Feature & $\begin{array}{l}\text { Attractions and entertainment } \\
(\%)\end{array}$ & $\begin{array}{l}\text { Restrooms } \\
(\%)\end{array}$ & $\begin{array}{l}\text { Parking location } \\
(\%)\end{array}$ \\
\hline \multicolumn{4}{|l|}{ Feature set } \\
\hline 1. + I think that the feature is useful and unique & 75 & 75 & 100 \\
\hline 2. + I think that the feature match the my needs & 100 & 100 & 100 \\
\hline \multicolumn{4}{|l|}{ User experience } \\
\hline 3.- The Main page button is not clearly visible & 25 & & \\
\hline 4.- The current location button is not clearly visible & 25 & & \\
\hline 5. + I can see the details clearly & 50 & 75 & 75 \\
\hline 6. + I think that this design looks modern & 75 & 75 & 50 \\
\hline $\begin{array}{l}\text { 7. + "Get Direction" button to navigate to the location is clearly } \\
\text { visible }\end{array}$ & 75 & 50 & 0 \\
\hline \multicolumn{4}{|l|}{ Communication: Messaging } \\
\hline 8.- Do not understand the meaning of the text in the application & 25 & 0 & 0 \\
\hline 9. + The map clearly shows the details of the route & 75 & 75 & 75 \\
\hline Total & 75 & 78 & 72 \\
\hline
\end{tabular}


Table 7 Users' feedback summary

\begin{tabular}{|c|c|c|c|c|c|c|}
\hline Feedback & User1 & User2 & User3 & User4 & $\%$ & Summary \\
\hline \multicolumn{7}{|l|}{ Attraction and Entertainment } \\
\hline Image/symbol are not understandable & $\boldsymbol{V}$ & & & & 25 & $\times$ \\
\hline Information of the total number of seats and total number of seats available & & $\boldsymbol{V}$ & & & 25 & $\boldsymbol{V}$ \\
\hline Optimize route and time & & & $\checkmark$ & & 25 & $\times$ \\
\hline Seat reservation system & & & $\boldsymbol{V}$ & & 25 & $\boldsymbol{V}$ \\
\hline The Pathway of map is unclear & & & & $\checkmark$ & 25 & $\boldsymbol{V}$ \\
\hline Information on the duration of each show & & $\checkmark$ & $\checkmark$ & & 50 & $\boldsymbol{V}$ \\
\hline \multicolumn{7}{|l|}{ Restroom Info } \\
\hline Lack of information about the availability of male urinal & & $\checkmark$ & & & 25 & $\boldsymbol{V}$ \\
\hline Add information about baby diaper changing table & & $\checkmark$ & $\boldsymbol{V}$ & & 50 & $\boldsymbol{V}$ \\
\hline \multicolumn{7}{|l|}{ Save Parking Location } \\
\hline Add accessible parking space & & $\checkmark$ & & & 25 & $\checkmark$ \\
\hline Inconsistency Image/Icon & & & & $\checkmark$ & 25 & $\boldsymbol{V}$ \\
\hline \multicolumn{7}{|l|}{ Overall App } \\
\hline The font size in map and in pop-up window is too small & $\checkmark$ & & & $\checkmark$ & 50 & $\checkmark$ \\
\hline The pop-up windows have no close button & & & & $\boldsymbol{V}$ & 25 & $\boldsymbol{V}$ \\
\hline The position of icon/bottom is not when consistency & & & & $\checkmark$ & 25 & $\times$ \\
\hline
\end{tabular}

and save its location and find the directions from your current location to the parking space (Table 6,7).

The result of the usability testing of considering each feature found that attractions and entertainment, which are common features, is received usability of score $75 \%$. Restrooms and parking location, which are our performance features, are $78 \%$ and $72 \%$ consequently. In summary, our latest prototype obtains an overall score of $75 \%$ which means that users' perception of our prototype is at the upper marginal. Users also think that the app is easy to use and has a degree of usefulness. We also obtain insights from user feedback to help us further improve the application.

\section{Conclusion}

Design thinking and lean concepts have helped us efficiently developed prototypes that are able to satisfy the targeted users in both terms of interface and functionality. Through the loops of usability tests, we have a solid idea of what users really need which we have put our effort to bring such an idea in prototype refinements. Although it still is not perfect, our latest prototype version has received a welcome result for both overall usefulness and ease of use. We decided to keep developing the app, hoping that it may help alleviate the current pain points which, therefore, provide our users a better and more memorable experiences during visiting a theme park.

\section{Limitations and Future Works}

The prototypes in this study consist of mock-up information and contain only basic features that we extracted from the user need and prioritized due to our short timeline and limit resources. A complete theme park mobile application contains a lot more features and functions. We planned to continue to enhance and develop the app as the following aspects:

- Include all the skipped features and delighter features.

- Expand the target group to cover more age generations and further do comparative studies between different generations, e.g., gen $\mathrm{Y}$ and $\mathrm{Z}$ or Gen $\mathrm{Z}$ and alpha.

- Develop synergies with theme park operators to obtain real information and create real-specific theme park maps.

Furthermore, it would be useful to take the COVID-19 pandemic into account and develop a feature to lessen the risk and increase hygiene consciousness so that customers can visit the park with confidence. 


\section{Appendices}

\section{Maze Tool Analytics for Prototypes}

\section{Forth Usability Testing: MVP Prototype 1.1}

A Maze is a usability testing tool that can get quantitative data such as success rates, misclick rates, and duration and review heatmaps for each screen in your prototype. The results of the analysis are as follows.

\section{Features: Attractions}

Task 1: Go to the home page to access the Attractions menu and choose the attractions with the shortest wait times and find directions to the attraction place (Figs. 17, 18).

\begin{tabular}{|c|c|c|c|c|c|}
\hline USABLLTYY SCOR & & & 79 & & \\
\hline $\begin{array}{l}\text { P. } \\
\text { AVG. TIME }\end{array}$ & $\cdot 17 \mathrm{~s}$ & $\cdot 5 \mathrm{~s}$ & $\cdot 23 \mathrm{~s}$ & $\cdot 3 s$ & $\cdot 14 \mathrm{~s}$ \\
\hline MiscLICK RATE & $\bullet 0 \%$ & $\bullet 0 \%$ & - $25 \%$ & • $0 \%$ & $\bullet 0 \%$ \\
\hline $\begin{array}{l}\text { } \\
\text { SCREEN }\end{array}$ & 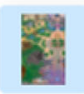 & 新 & 5 & 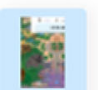 & $\equiv$ \\
\hline & Screen 1 & Screen 2 & Screen 3 & Screen 4 & Screen 5 \\
\hline
\end{tabular}

Fig. 17 Usability stats of features attractions form analysis report maze web application

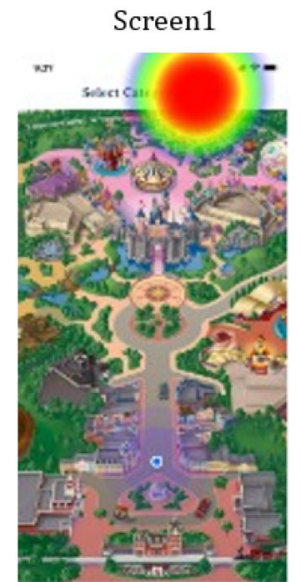

- $\oplus \cap=$

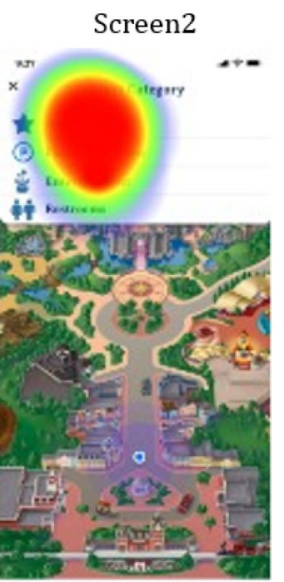

ค $\odot Q \equiv$

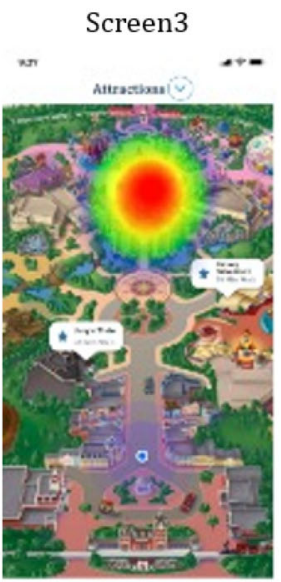

$\wedge \odot \oplus Q \equiv$

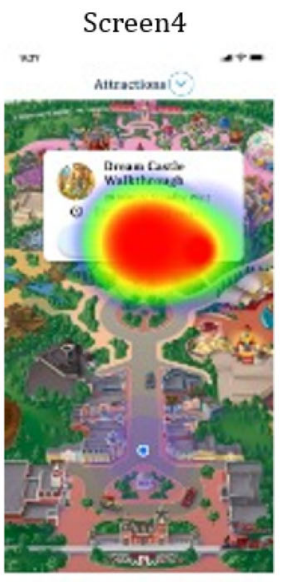

$\bullet \oplus Q \equiv$

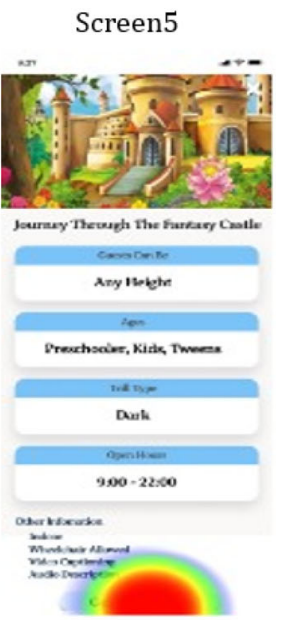

Fig. 18 Optimal path navigation, bounce, and usability for each screen of features attractions form analysis report maze web application 


\section{Features: Entertainment}

Task 2: Go to the home page to access the Entertainment menu and choose the Entertainment data to find showtimes of The Magic Piano Player and find directions to The Magic Piano Player place (Figs. 19, 20).

\section{Features: Real-time Restroom Info}

Task 3: Find the nearest restroom and check that men's restrooms are available and show directions map to the restroom (Figs. 21, 22).

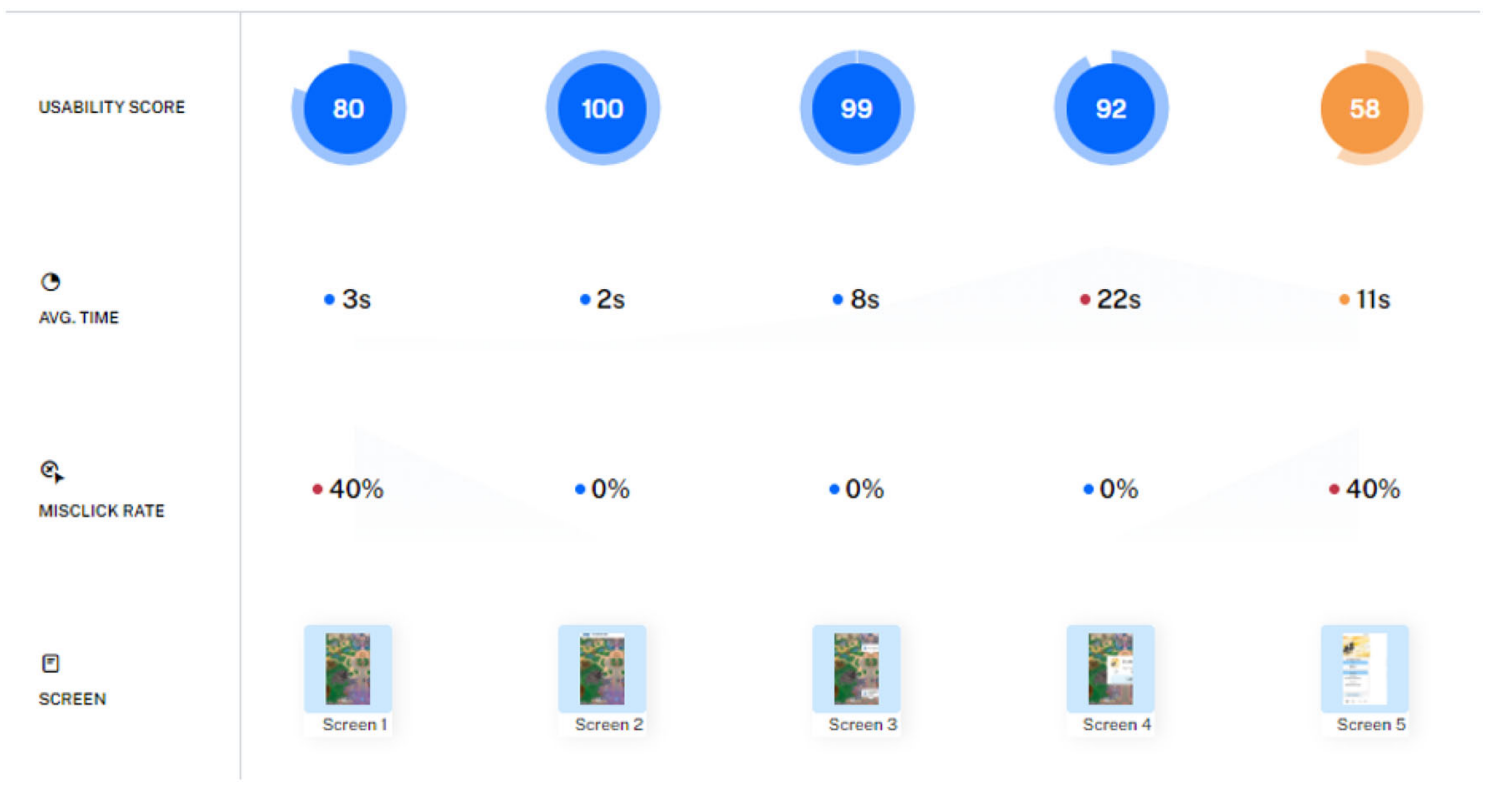

Fig. 19 Usability stats of features entertainment form analysis report maze web application

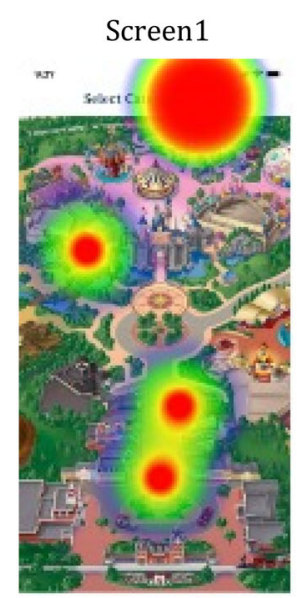

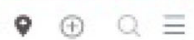

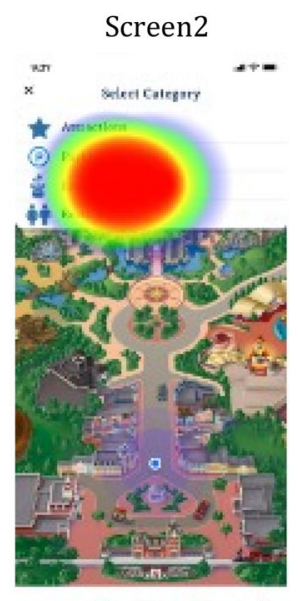

- $(+) \equiv$

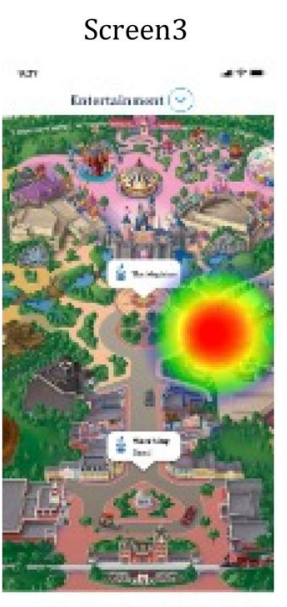

$\wedge \bullet \oplus Q$
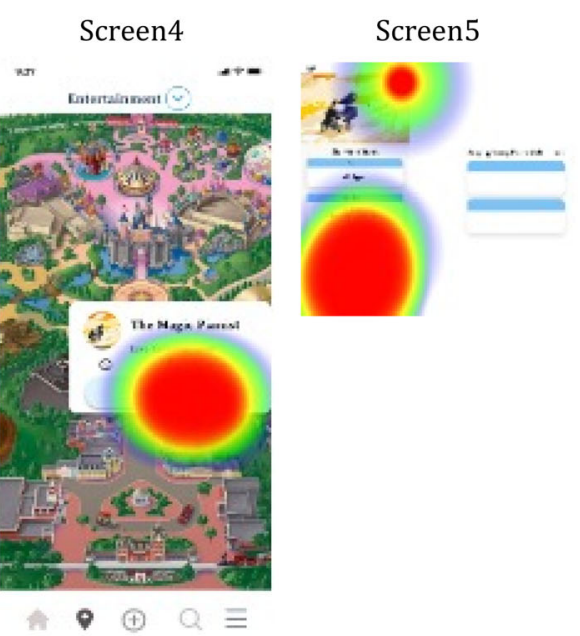

Fig. 20 Optimal path navigation, bounce, and usability for each screen of features entertainment form analysis report maze web application 


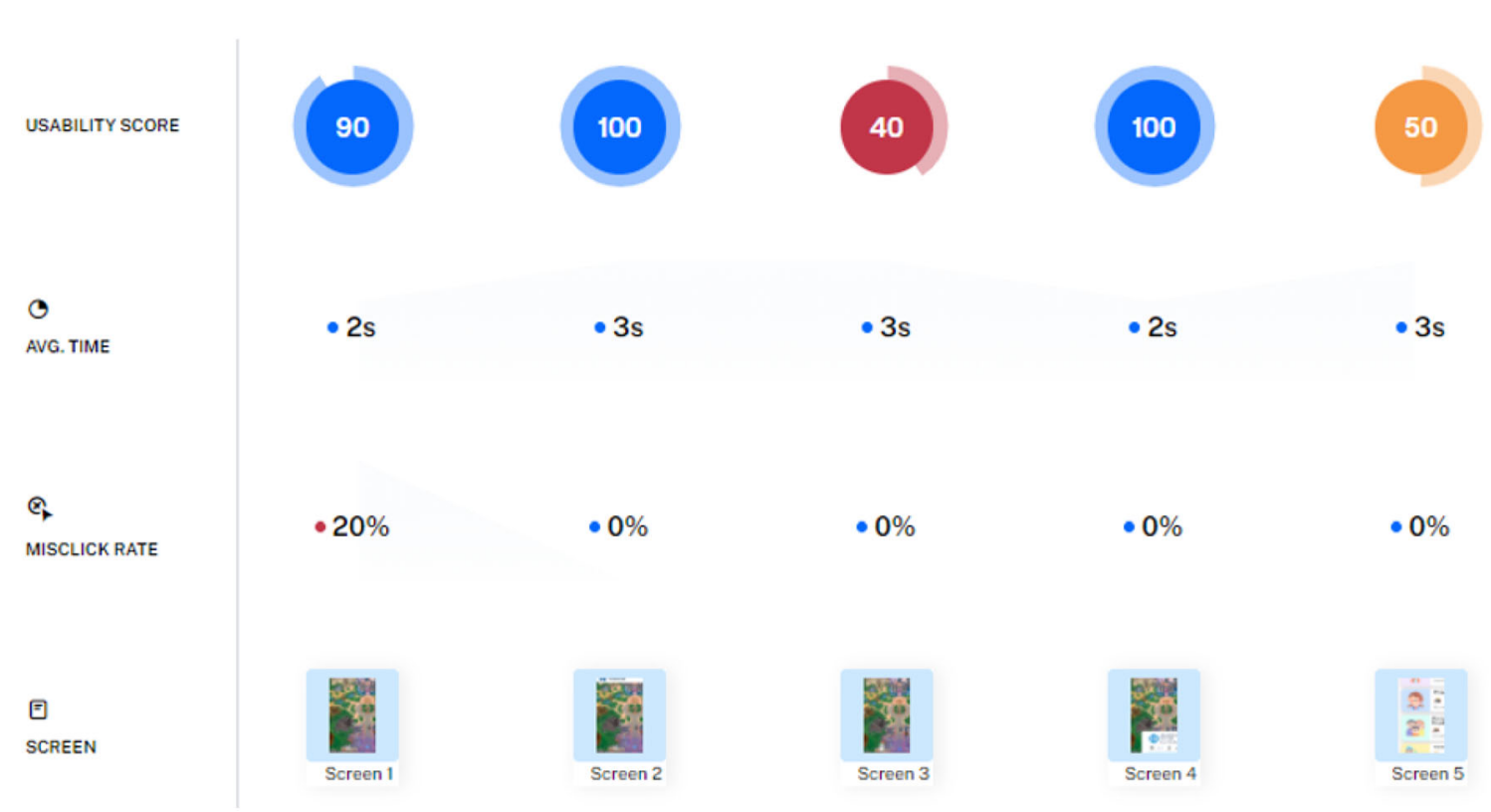

Fig. 21 Usability stats of features Real-time Restroom Info form analysis report maze web application

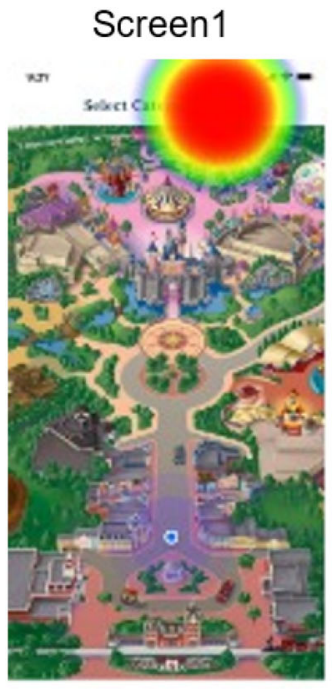

A $\odot Q \equiv$

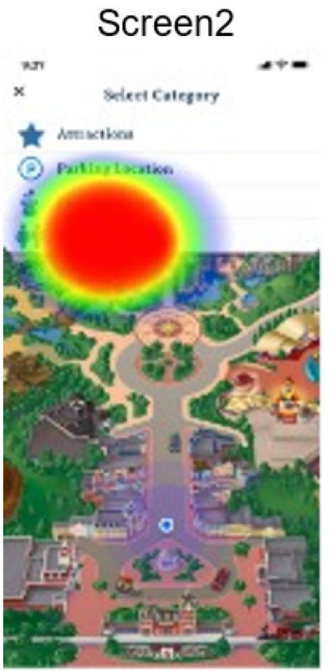

- $\odot Q \equiv$
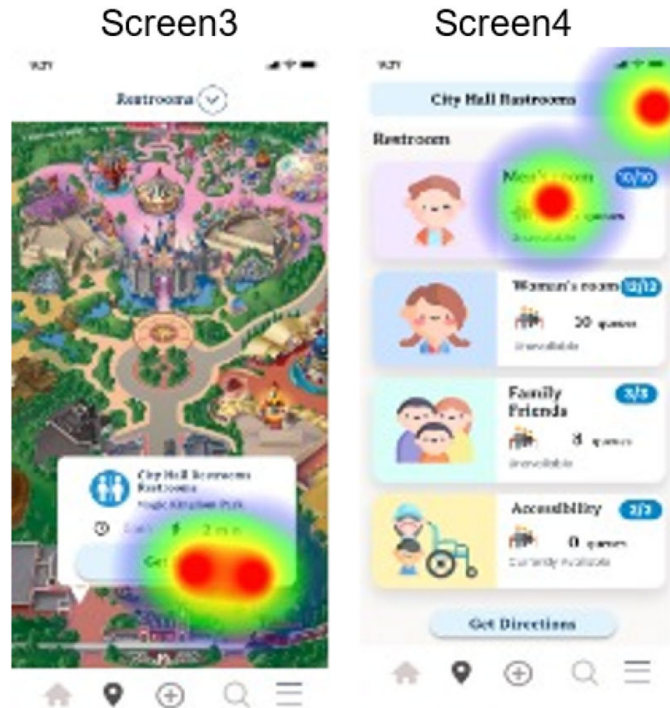

Fig. 22 Optimal path navigation, bounce and usability for each screen of features Real-time Restroom Info form analysis report maze web application 


\section{Features: Saving Parking Location}

Task 4: From the home page, please click to access the feature 'Parking Location and choose the feature to access
Parking Location menu and choose parking space to park and find the directions from your current location to the parking space (Figs. 23, 24).

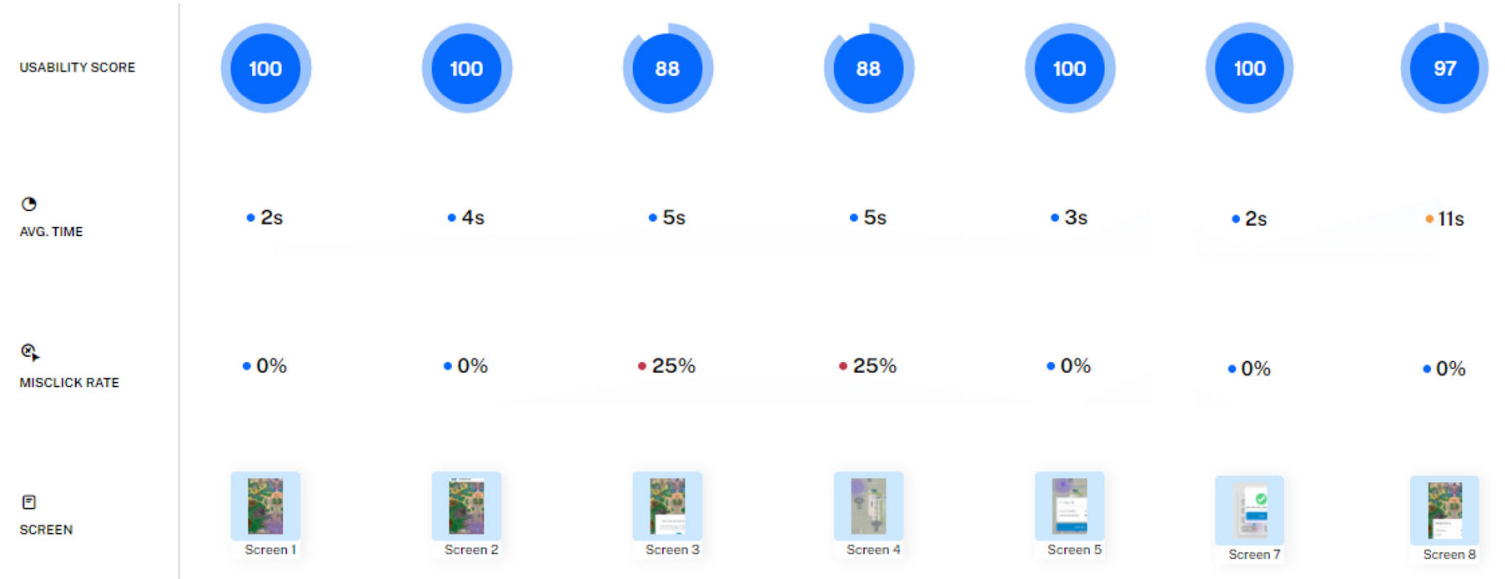

Fig. 23 Usability stats of features Saving Parking Location form analysis report maze web application
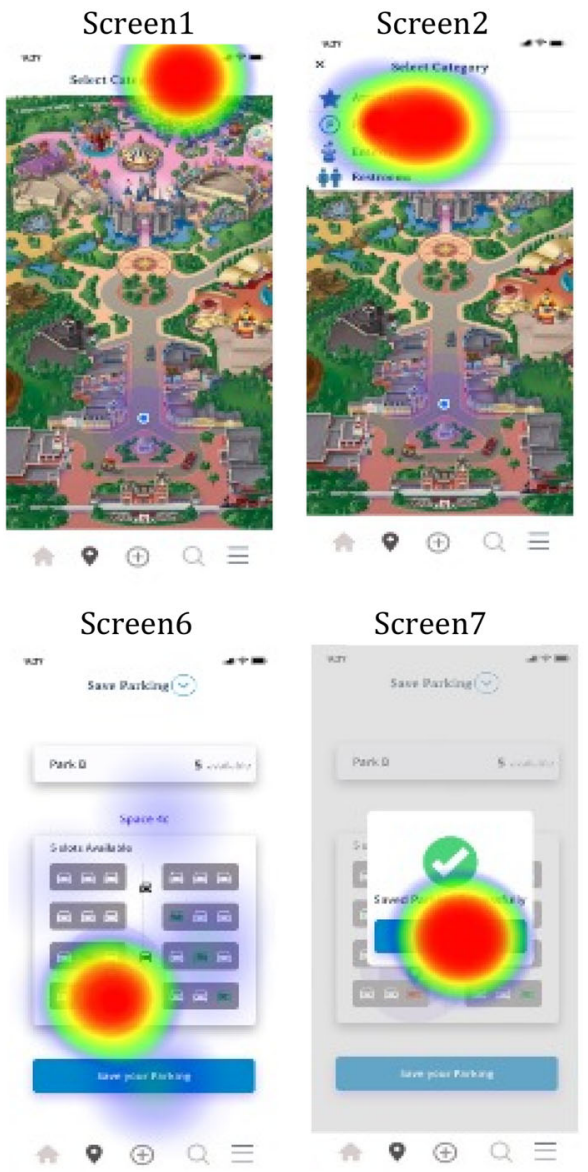
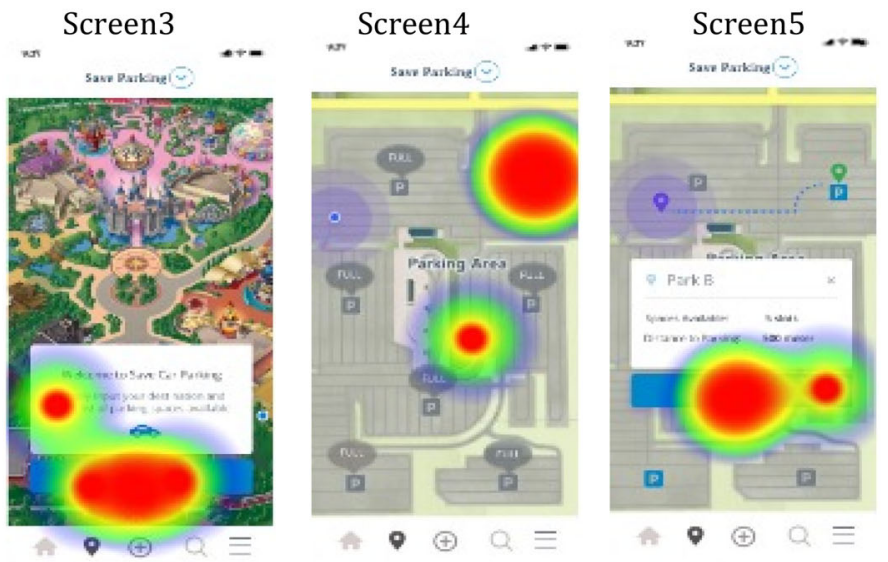

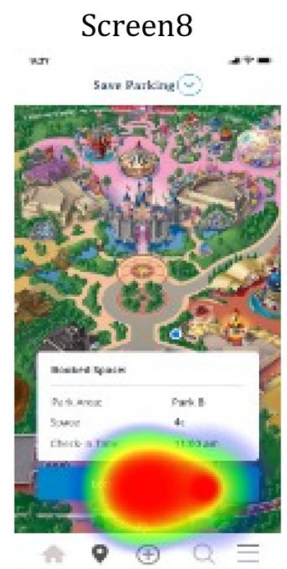

Fig. 24 Optimal path navigation, bounce and usability for each screen of features Saving Parking Location form analysis report maze web application 


\section{High-Fidelity Design link: https://www. figma.com/file/ BfCWfeCRDm5eQUFpHvwpMG/Theme-Park- Project}

See Fig. 25.

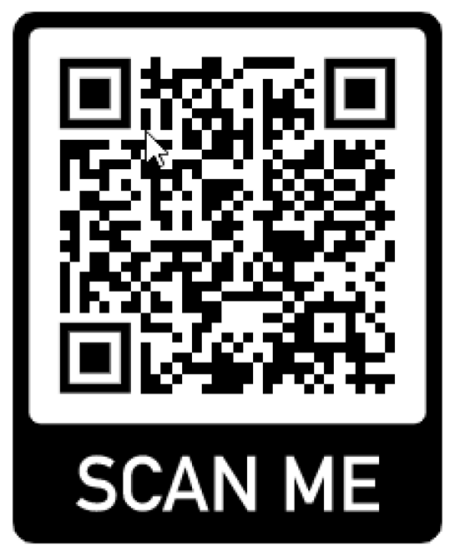

Fig. 25 QR Code Theme Park Application High-Fidelity Design

\section{References}

1. Milman A, Tasci ADA, Wei W (2020) Crowded and popular: the two sides of the coin affecting theme-park experience, satisfaction, and loyalty. J Destin Mark Manag. https://doi.org/10.1016/j. jdmm.2020.100468.100468 (ISSN 2212-571X)

2. Rubin J (2019) 2018 TEA/AECOM Them Index and Museum Index [Online]. Theme Entertainment Association/Economics Research Associations. Retrieved on 7/8/2021 from https://www. teaconnect.org/images/files/TEA_328_381804_190528.pdf

3. Rubin J (2020) 2019 TEA/AECOM Them Index and Museum Index [Online]. Theme Entertainment Association/Economics Research Associations. Retrieved on 7/8/2021 from https://www. teaconnect.org/images/files/TEA_369_18301_201201.pdf.

4. Zambetta $F$ et al (2020) Reducing perceived waiting time in theme park queues via an augmented reality game. ACM Trans Comput-Hum Interact 27(1):1-30. https://doi.org/10.1145/ 3361524
5. Barnes SJ, Mattsson J, Sorensen F (2016) Remembered experiences and revisit intentions: a longitudinal study of safari park visitors. Tour Manag 57:286-294. https://doi.org/10.1016/j.tour man.2016.06.014 (ISSN 0261-5177)

6. Hu X, Wang S, Li Y (2020) The user experience research of theme park app: a case study of Shanghai disney resort. Adv Soc Sci Educ Humanit Res 416:383-387. https://doi.org/10.2991/ assehr.k.200316.086

7. Dennehy D, Kasraian L, O'Raghallaigh P, and Conboy K (2016) Product Market Fit Frameworks for Lean Product Development [Online]. R\&D Management Conference 2016 "From Science to Society: Innovation and Value Creation". Retrieved on 7/8/2021 from https://dora.dmu.ac.uk/bitstream/handle/2086/17071/Den nehy\%20et\%20al._2016_Product\%20Market\%20Fit\%20Frame works $\% 20$ for\%20Lean $\% 20$ Product $\% 20$ Development.pdf?se quence $=1 \&$ isAllowed $=y$

8. Anonymous. What is Interactive Design? [Online]. Interaction Design Foundation. Retrieved on 7/8/2021 from https://www. interaction-design.org/literature/topics/interaction-design.

9. Keinonen T (2008) User-centered Design and Fundamental Need. I: Proceeding of the 5th Nordic Conference on HCI, pp. 211-219. https://dl.acm.org/doi/proceedings/https://doi.org/10.1145/ 1463160

10. Anonymous. Usability [Online]. Interaction Design Foundation. Retrieved on 7/8/2021 from https://www.interaction-design.org/ literature/topics/usability.

11. Anonymous, 5 Stages in The Design Thinking Process [Online]. Interaction Design Foundation. Retrieved on 7/8/2021 from https://www.interaction-design.org/literature/article/5-stages-inthe-design-thinking-process.

12. Sandorova Z, Repanova T, Palencikova Z, Betak N (2020) Design thinking - a revolutionary new approach in tourism education? J Hosp Leis Sport Tour Educ 26:1-9. https://doi.org/10. 1016/j.jhlste.2019.100238

13. dos Santos TB et al (2021) Prototyping for user involvement activity: how to achieve major benefit. CIRP J Manuf Sci Technol 33:465-472. https://doi.org/10.1016/j.cirpj.2021.04.013 (ISSN 1755-5817)

14. Martin N, Dominique-Ferreira S, Pinheiro C (2021) Bridging tourism, architecture, and sustainability: design and development of an app for contemporary architecture built in Portugal. J Glob Sch Market Sci. https://doi.org/10.1080/21639159.2020.1808853

15. Smyk A (2020) The System Usability Scale \& How It's Used in UX [Online]. Retrieved on 1/8/2021 from https://xd.adobe.com/ ideas/process/user-testing/sus-system-usability-scale-ux

Publisher's Note Springer Nature remains neutral with regard to jurisdictional claims in published maps and institutional affiliations. 